\title{
Building a better work/life balance
}

\section{Parul Pahal, MD, and Steven Lippmann, MD}

$\mathrm{P}$ hysician burnout is a common and serious problem. In a 2017 survey of $>14,000$ US physicians across 27 specialties, $42 \%$ reported burnout, ${ }^{1}$ which typically is defined as a long-term stress reaction marked by emotional exhaustion, depersonalization, and a lack of sense of personal accomplishment. ${ }^{2}$

Creating a focused, yet comfortable professional life is essential for preventing burnout. For our patients' sake and for our own personal fulfillment, there is much we can do to maintain a healthy professional and home life balance. This article describes the factors that contribute to physician burnout, and outlines steps you can take to improve your work/life balance.

\section{The multifactorial roots of stress}

Many physicians frequently blend their professional and personal lives. Most are absorbed in their practices, which leaves limited time for family interactions, daily life, or wellness.

Work hours are often long, and schedules are filled with obligations. In recent years, changes to medical practice have resulted in many additional responsibilities for physicians, such as administrative tasks and adapting to electronic health care, particularly to the use of electronic health records (EHRs). This has escalated workload and worries while diminishing patient interaction, creating more distant clinical relationships and providing less financial remuneration. Monetary pressures to see more patients limit the quality of care. Overload often forces physicians to stay at work late and/or labor excessive hours at home with less family interac- tion. The introduction of EHRs escalated this trend, while detracting from a healthy family, personal, and professional life. Addressing cumbersome documentation requirements while striving to maintain contact with patients is frustrating. ${ }^{3}$

Physician job dissatisfaction has worsened over time. Burnout escalates errors, diminishes patient rapport and safety, and produces suboptimal outcomes, all resulting in declining professional satisfaction.

\section{Improving your work/life balance}

The following strategies can help you make changes to better balance your professional and personal lives.

Assess priorities and goals. Before taking steps to achieve an optimal work-home balance, first review medical, spousal, and parental expectations. Social support is key.

Identify stressors. Use self-report questionnaires and collegial discussions to assess for the presence and/or severity of burnout. Prevention and/or intervention at personal and organizational levels can positively impact physician well-being. ${ }^{4}$

Focus on self-care. Prioritize your personal health care, sleep hygiene, exercise routines, quality of diet, and recreational activi-

\section{Every issue of CURRENT PsychiatRY} has its 'Pearls'

\section{Yours could be found here.}

Read the 'Pearls' guidelines for manuscript submission at MDedge.com/ CurrentPsychiatry/page/pearls. Then, share with your peers a 'Pearl' of wisdom from your practice.
Dr. Pahal is a Research Associate, Internal Medicine - Infectious Disease Division, University of Louisville, Louisville, Kentucky. Dr. Lippmann is a Family Medicine Physician and Emeritus Professor of Psychiatry, University of Louisville, Louisville, Kentucky.

Disclosures

The authors report no financial relationships with any companies whose products are mentioned in this article, or with manufacturers of competing products.

doi: $10.12788 / \mathrm{cp} .0158$ 


\section{Work to modify} regulations that require physicians to spend time on nonclinical tasks ties. Do not self-prescribe medications, and avoid excessive alcohol use. ${ }^{5}$

Make changes to your practice. In your office, make efforts to maximize social connectiveness. Consider assigning routine tasks to other staff members. Upgrading your typing skills, employing medical records scribes, and/or using voice recording systems can reduce your workload. ${ }^{5}$

Advocate for better legislation. Both through professional medical organizations and at government levels, work to modify regulations that require physicians to spend their time on nonclinical tasks. This might include advocating to simplify EHRs and insurance company reimbursement requirements to decrease paperwork and reduce barriers to prescribing. Stress management seminars, which typically are offered at state and national conferences, can foster interpersonal and professional competencies throughout one's medical career. $^{6}$ Medical licensure boards should make efforts to reduce the stigma of reporting mental health issues; they should assure confidentiality protection and help for those who seek assistance. ${ }^{5}$

\section{References}

1. Peckham C. Medscape psychiatrist lifestyle report: race and ethnicity, bias and burnout. Medscape. Published January 11 2017. Accessed July 12, 2021. http:/ / www.medscape.com/ features/slideshow/lifestyle/2017/psychiatry\#page=1

2. Agency for Healthcare Research and Quality. Physician burnout. Published July 2017. Accessed July 13, 2021. https: / / www.ahrq.gov/prevention/clinician/ahrqworks/burnout/index.html

3. Lippmann S. Can shrinks "shrink" the electronic health record? Internet and Psychiatry. December 19, 2019. Accessed on August 15, 2020. https://www.internetandpsychiatry. com/wp/editorials/can-shrinks-shrink-the-electronichealth-record/

4. West CP, Dyrbye LN, Erwin PJ, et al. Interventions to prevent and reduce physician burnout: a systematic review and meta-analysis. Lancet. 2016;388(10057): 2272-2281.

5. Mohanty D, Prabhu A, Lippmann S. Physician burnout: signs and solutions. J Fam Pract. 2019;68(8):442-446.

6. McCue JD, Sachs CL. A stress management workshop improves residents' coping skills. Arch Intern Med. 1991; 151(11):2273-2277. 